EDITORIAL

\title{
CINQUENTENÅRIO DA UNIVERSIDADE DE SÃO PAULO
}

A Universidade de São Paulo foi fundada em 25 de janeiro de 1934 pelo então Governador Armando Salles de Oliveira, e incorporou a experiência das grandes escolas já existentes na época, tais como, Faculdade de Direito, Faculdade de Medicina, Escola Politécnica, Escola Prática de Agricultura "Luiz de Queiroz", Faculdade de Farmácia e Odontologia e Escola de Medicina Veterinária.

Em 1934, após a revolução constitucionalista de 1932, a elite intelectual de São Paulo resolveu transformar a frustração dominante na área política em algo positivo na área intelectual. Para essa renovação, criou a Faculdade de Filosofia, Ciências e Letras que abrangia as áreas de Química, Ciências, Geografia e História, Ciências Sociais, Letras, Màtemática e Física.

Muitos professores estrangeiros, especialmente, franceses, alemães, italianos e portugueses, contribuiram para a implantação, em 1934, da Faculdade de Filosofia Ciências e Letras, que mais tarde foi subdividida em diversos institutos e deu origem à atual Faculdade de Filosofia, Letras e Ciências Humanas, dando-lhe uma base sólida literária e humanística.

A Universidade de São Paulo perfaz um total de 33 unidades de ensino, distribuídas pelos "campi" de São Paulo, Piracicaba, Bauru, Ribeirão Preto e São Carlos; além de manter 4 museus: o Museu Paulista e o Museu de Zoologia no Ipiranga; o Museu de Arte Contemporânea, no Ibirapuera, o Museu de Arqueologia e Etnologia na Cidade Universitária.

A população estudantil é de $40 \mathrm{mil}$ alunos, 30 mil de graduação e 10 mil de pós-graduação, contando com 4.803 docentes nos diversos níveis.

A Escola de Enfermagem, criada em 31 de outubro de 1942, portanto, 8 anos após a fundação da Universidade de São Paulo, encontra-se, neste ano do Cinquentenário, completamente integrada à estrutura universitária, contando, além do Curso de Graduação, com Cursos de Pós-Graduação Nível de Mestrado e Doutorado. Seus docentes desenvolvem pesquisas de boa qualidade e prestam relevantes serviços à comunidade, tornando-a importante patrimônio sócio-cultural de São Paulo e do Brasil.

Profa. Dra. Leda Ulson Mattos 